\title{
Metagenomic Next-Generation Sequencing Reveal Presence of a Novel Ungulate Bocaparvovirus in Alpacas
}

\author{
Deepak Kumar ${ }^{1}{ }^{10}$, Suman Chaudhary ${ }^{1}$, Nanyan Lu ${ }^{1}$, Michael Duff ${ }^{1}$, Mathew Heffel ${ }^{1}$, \\ Caroline A. McKinney ${ }^{2}$, Daniela Bedenice ${ }^{2}$ and Douglas Marthaler ${ }^{1, *}$ \\ 1 Kansas State Veterinary Diagnostic Laboratory, College of Veterinary Medicine, Kansas State University, \\ Manhattan, KS 66506, USA \\ 2 Department of Clinical Sciences, Cummings School of Veterinary Medicine at Tufts University, 200 Westboro \\ Road, North Grafton, MA 01536, USA \\ * Correspondence: marth027@umn.edu
}

Received: 24 May 2019; Accepted: 27 July 2019; Published: 31 July 2019

\begin{abstract}
Viruses belonging to the genus Bocaparvovirus ( $\mathrm{BoV})$ are a genetically diverse group of DNA viruses known to cause respiratory, enteric, and neurological diseases in animals, including humans. An intestinal sample from an alpaca (Vicugna pacos) herd with reoccurring diarrhea and respiratory disease was submitted for next-generation sequencing, revealing the presence of a BoV strain. The alpaca BoV strain (AlBoV) had a $58.58 \%$ whole genome nucleotide percent identity to a camel BoV from Dubai, belonging to a tentative ungulate BoV 8 species (UBoV8). Recombination events were lacking with other UBoV strains. The AlBoV genome was comprised of the NS1, NP1, and VP1 proteins. The NS1 protein had the highest amino acid percent identity range (57.89-67.85\%) to the members of UBoV8, which was below the $85 \%$ cut-off set by the International Committee on Taxonomy of Viruses. The low NS1 amino acid identity suggests that AlBoV is a tentative new species. The whole genome, NS1, NP1, and VP1 phylogenetic trees illustrated distinct branching of AlBoV, sharing a common ancestor with UBoV8. Walker loop and Phospholipase A2 (PLA2) motifs that are vital for virus infectivity were identified in NS1 and VP1 proteins, respectively. Our study reports a novel BoV strain in an alpaca intestinal sample and highlights the need for additional BoV research.
\end{abstract}

Keywords: alpaca; virus; Bocaparvovirus; genome; next-generation sequencing; metagenomics

Bocaparvoviruses (BoVs) belong to the genus Bocaparvovirus and are emerging pathogens of the Parvoviridae family. BoVs are nonenveloped, single-stranded DNA viruses with an icosahedral symmetry and were originally named according to their first identified members, bovine parvovirus (BPV) and minute virus of canine (MVC) [1]. In the past few years, novel BoVs have been identified in a variety of animals, including bats [2], camels [3], gorillas [4], marmots [5], pigs [6], and rodents [7]. BoVs are comprised of 21 species, including carnivore BoV 1-6, chiropteran BoV 1-4, lagomorph BoV 1, pinniped BoV 1 and 2, primate BoV 1 and 2, and ungulate BoV (UBoV) 1-6. A few new UBoVs have been identified in dromedary camels (tentatively UBoV7 and UBoV8) [3] but have yet to be classified by the International Committee on Taxonomy of Viruses (ICTV).

Initially, the classification of parvoviruses required the isolation of the virus; however, reporting of the viral sequence containing all the non-structural and structural coding regions is now acceptable provided the genomic, serological, or biological data supports infectious etiology [8]. Most of the members of the Bocaparvovirus genus have been identified using molecular methods and lack isolation in cell culture $[3,4,9]$. Human BoVs cause severe respiratory and gastrointestinal infections in young children [10]. Bovine parvovirus (BPV) causes gastrointestinal and respiratory symptoms, reproductive 
failure, and conjunctivitis in cattle worldwide [11]. Another important member of the BoV genus, canine minute virus (MVC), causes sub-clinical disease and fetal infections often leading to neonatal respiratory disease or abortions [12]. However, Koch's postulates have yet to be fulfilled to link newly emerging BoVs with the clinical disease in animals $[1,3,5]$.

Alpaca (Vicugna pacos) are domesticated members of the new world camelids closely related to llama (Lama glama), guanaco (Lama guanicoe), and vicuna (Vicugna vicugna) [13]. Over the past couple of decades, alpacas have gained significant popularity as pets, show animals, and fiber animals in the United States, with a total of 264,587 alpacas registered in the US as of May 2019 [14]. A variety of viruses have been identified in alpacas, including bovine viral diarrhea virus, coronavirus, adenovirus, equine viral arteritis virus, rotavirus, rabies, bluetongue virus, foot-and-mouth disease virus, bovine respiratory syncytial virus, influenza A virus, bovine papillomavirus, vesicular stomatitis virus, parainfluenza-3 virus, West Nile virus, and equine herpesvirus [12,15-20]. However, BoVs have yet to be reported in alpacas.

An alpaca farm in the mid-eastern United States reported recurrent diarrhea and respiratory failure in young alpacas, with a case fatality rate up to $100 \%$. In 2017, an alpha coronavirus was identified as causing clinical disease in two animals, and vaccination was subsequently attempted. However, diarrhea and respiratory distress continued to occur in juvenile animals despite increased biosecurity measures and supportive herd management. In 2018, an intestinal sample from a deceased alpaca was submitted to Kansas State University Veterinary Diagnostic Laboratory for metagenomic next-generation sequencing (NGS) to further evaluate potential causes of disease. The intestinal sample was processed, extracted, and sequenced using previously described methods [21,22]. The raw data was analyzed using a custom bioinformatic pipeline [23]. Reads were trimmed, and the adapter/index sequences were removed using Trimmomatic [24], Sickle [25], and Scythe [26].

A total of 334,052 cleaned reads were classified as eukaryotes (41\%), bacteria (28\%), viral (7\%), and other organisms (4\%) by Kraken software, which applies a $k$-mer search strategy from a sequence database to taxonomically classify reads (Figure 1) [27]. Kraken revealed a majority of the viral reads $(22,170)$ as $\mathrm{BoV}(77 \%)$; bacteriophages $(14 \%)$; and miscellaneous viruses composed of retroviruses, bacteria viruses, and unclassified viruses (9\%). Reads lacking classification (no hits, $n=67,604$ ) and identified as viral reads $(n=22,170)$ were de novo assembled into contigs and BLAST (Basic Local Alignment Search Tool) against the National Center for Biotechnology Information (NCBI) database, identifying a contig with a 58.58\% nucleotide percent identity to a camel BoV from Dubai (KY640435). A full-length genome (5155 nucleotides) of an alpaca BoV (AlBoV, GenBank number MK014742) had an average read coverage of 2440X. AlBoV was aligned with the 108 complete UBoV genomes from GenBank using Multiple Alignment using Fast Fourier Transform (MAFFT) [28] in Geneious Prime [29]. AlBoV shared a $57.77-58.58 \%$ whole genome nucleotide identity to the UBoV8 strains (Table 1). Recombination events were not detected in the UBoV alignment using RDP4 software [30], although single-stranded DNA viruses such as parvoviruses possess a mutation rate similar to single-stranded RNA viruses and a higher mutation rate than double-stranded DNA viruses [31].

AlBoV contained three open reading frames (ORFs), NS1, NP1, and VP1/VP2, which were $2154 \mathrm{bp}$ (411 to $2564 \mathrm{bp}$ ), $507 \mathrm{bp}$ (2701 to $3207 \mathrm{bp}$ ), and 1395bp (3194 to $4588 \mathrm{bp}$ ), respectively. ICTV indicates a new parvovirus species should have less than $85 \%$ amino acid identity of the NS1 protein with other parvovirus species. The AlBoV identified in the present study shared the highest NS1 amino acid percent identity (57.89-67.85\%) with camel BoVs in UBoV8 (Table 1) and represents a tentative new BoV species, UBoV9. The ancillary protein NP1, which is a unique feature of BoVs, is known to influence RNA processing events by suppressing internal polyadenylation and splicing of an upstream intron [32]. Unlike some of the other BoV sequences, the coding region of NP1 of AlBoV did not overlap with the C-terminal region of NS1. Interestingly, VP1/VP2 gene of AlBoV was the shortest among the identified UBoVs in the GenBank (Figure 2). Frameshift mutation were lacking in the AlBoV VP1/VP2 sequence, and the nucleotide sequence after the VP1/VP2 stop codon varied among the 108 complete UBoV sequences in the GenBank. 


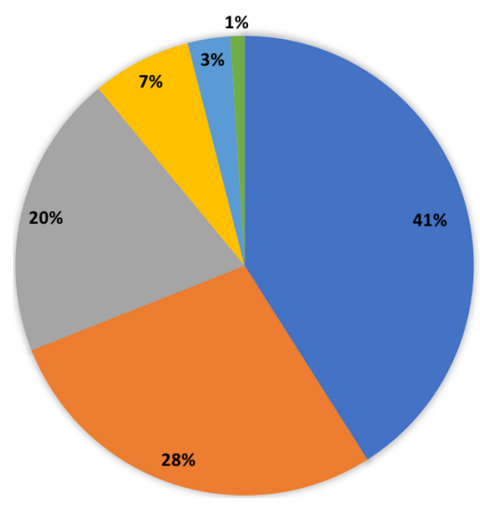

a

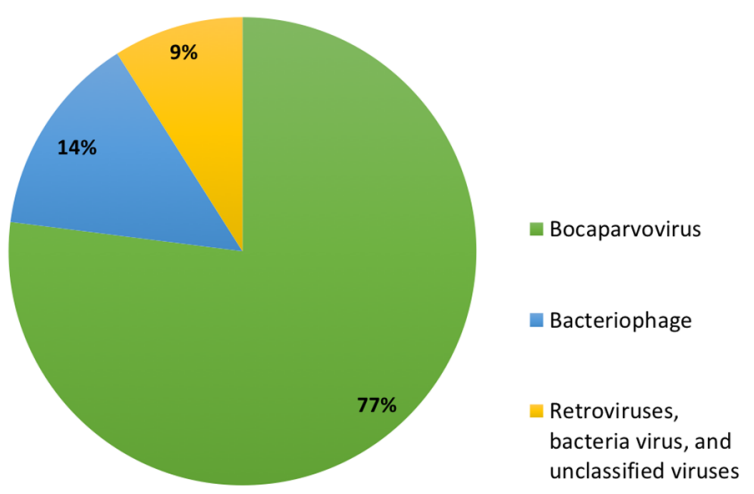

b

Figure 1. Metagenomic (a) and virome (b) results from the alpaca intestinal sample.

Table 1. Nucleotide (nt) and amino acid (aa) percent identities of NS1, NP1, and VP1 genes of the alpaca bocaparvovirus (AlBoV) compared to the other ungulate $\mathrm{BoV}(\mathrm{UBoV})$ sequences $(n=108)$.

\begin{tabular}{ccccccccc}
\hline \multirow{2}{*}{ UBoV Virus } & Species & \multirow{2}{*}{$\begin{array}{c}\text { Whole } \\
\text { Genome (nt) }\end{array}$} & \multicolumn{2}{c}{ nt } & aa & NS1 & NP1 & \multicolumn{2}{c}{ VP1 } \\
\cline { 4 - 9 } & & & & & aa & nt & aa \\
\hline UBoV1 $(n=2)$ & Bovine & $36.22-38.98$ & $33.32-37.70$ & $26.75-30.08$ & $35.14-35.42$ & $40.44-42.62$ & $36.51-36.72$ & $28.49-31.45$ \\
UBoV2 $(n=18)$ & Porcine & $37.20-39.61$ & $43.40-49.64$ & $36.18-40.34$ & $34.58-36.94$ & $31.89-37.84$ & $33.42-34.79$ & $27.03-28.65$ \\
UBoV3 $(n=6)$ & Porcine & $33.73-36.17$ & $45.64-45.83$ & $36.23-36.61$ & $34.13-34.49$ & 35.96 & $25.96-28.63$ & $20.10-20.83$ \\
UBoV4 $(n=5)$ & Porcine & $35.74-36.07$ & $45.66-45.95$ & $37.06-37.66$ & $34.89-35.61$ & $31.52-31.87$ & $27.20-27.64$ & $21.31-21.59$ \\
UBoV5 $(n=36)$ & Porcine & $44.37-47.32$ & $52.83-59.39$ & $46.58-52.8$ & $37.59-40.40$ & $34.78-40.53$ & $39.02-40.54$ & $30.76-35.81$ \\
UBoV6 $(n=2)$ & Bovine & $38.58-38.62$ & $37.60-38.01$ & 29.64 & 33.02 & $40.56-40.88$ & $36.17-36.32$ & $29.45-29.88$ \\
UBoV7 $(n=18)$ & Camel & $36.49-36.76$ & $39.01-39.64$ & $33.08-33.98$ & $36.91-38.93$ & $32.24-33.88$ & $26.05-27.11$ & $21.08-21.84$ \\
UBoV8 $(n=21)$ & Camel & $57.77-58.58$ & $67.64-69.26$ & $57.89-67.85$ & $46.99-52.47$ & $53.51-56.76$ & $45.05-46.36$ & $42.15-43.60$ \\
\hline
\end{tabular}

\footnotetext{
Alpaca/USA/2018/MK014742 UBoV1 Bovine/None/Abinanti/DQ335247

UBoV2 Porcine/CHN/HNZM/KX017193

UBoV3 Porcine/CHN/HB/HD/MG893897 UBoV4 Porcine/KOR/KU14/KJ622366 UBOVS Porcine/USA/IN109-2/KF025383 UBov6 Bovine/USA/USII/03/KU172421

UBoV7 Camel/ARE/208C-F/KY640449

UBov8 Camel/ARE/113C-F/KY640424
}

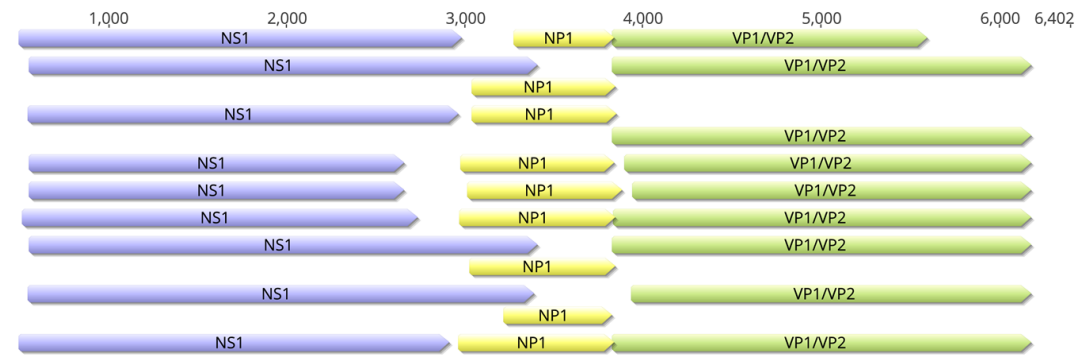

Figure 2. Genome organization of AlBoV compared to UBoV1-8. The purple, yellow, and green boxes indicate the NS1, NP1, and VP1/VP2 open reading frames (ORFs), respectively.

To study the phylogenetic relationship between AlBoV and other UBoVs, whole genome, NS1, NP1, and VP1 phylogenetic trees were created using a maximum likelihood method (phyML), using 500 bootstrap replicates in Geneious Prime. The trees were curated in FigTree (available from http://tree.bio.ed.ac.uk/software/figtree/) and Adobe Illustrator CS6 (Adobe Systems Inc, San Jose, CA, USA). Whole genome and NS1 phylogenetic trees illustrated that AlBoV shared a common ancestor with the UBoV8 species from camels (Figure 3). All eight species of UBoV (1-8) illustrated clear grouping in phylogenetic trees, which was observed in NP1 and VP1 phylogenetic trees as well. 
a.

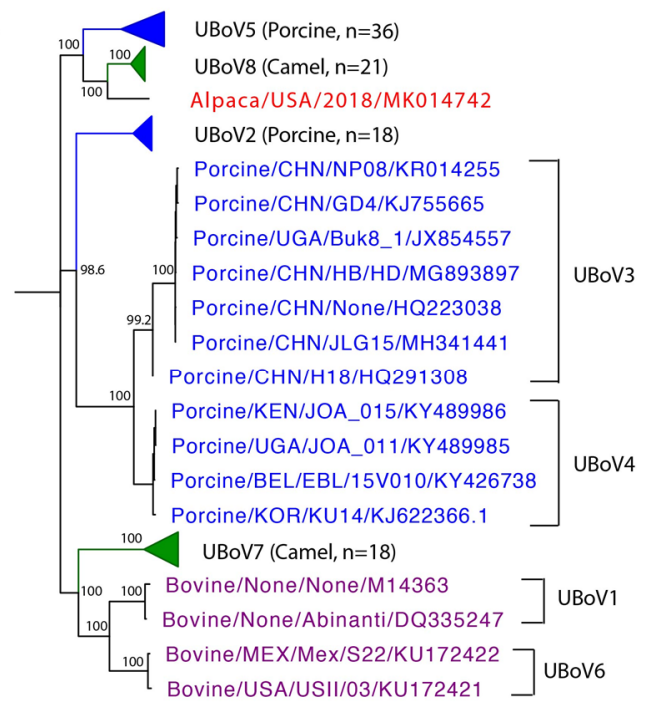

b.

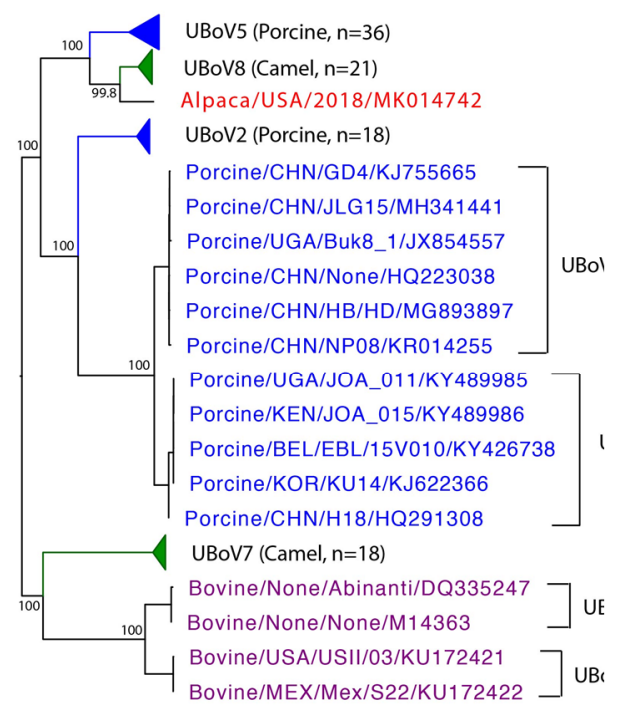

Figure 3. Mid-root Maximum Likelihood phylogenetic trees of AlBoV and other UBoV strains in the GenBank. (a) Whole genome phylogenetic tree. (b) Phylogenetic tree of NS1 amino acid sequences. Bootstrap values are indicated for major nodes. AlBoV is represented in red while the porcine, camel, and bovine UBoV strains are represented in blue, green, and purple, respectively.

To investigate and identify the presence of virulence attributes, AlBoV was screened for the ATP or GTP-binding Walker loop motif (GPASTGKT) and Phospholipase A2 (PLA2) motif with the calcium-binding loop and phospholipase catalytic residues; GPASTGKT and PLA2 were found in the NS1 and N-terminal of VP1 proteins, respectively (Figure 4). These protein motifs are conserved and are required for parvovirus infectivity. Phospholipase A2 activity, with the calcium-binding loop and phospholipase catalytic residues, is critical for efficient transfer of the viral genome from the late endosomes/lysosomes to the nucleus for the initiation of replication, and hence is considered essential for virus infectivity [33]. Mutations of critical amino acid residues in the VP1 protein of human parvovirus B19 induces a strong reduction in phospholipase A2 activity and virus infectivity [34]. Considering their vital role in parvovirus infectivity, PLA2 inhibitors are also targeted for antiviral drugs against parvovirus-associated diseases. The presence of the Walker loop and Phospholipase A2 motifs suggests that the newly identified alpaca BoV possesses the virulence determinants necessary to cause disease. 
a.
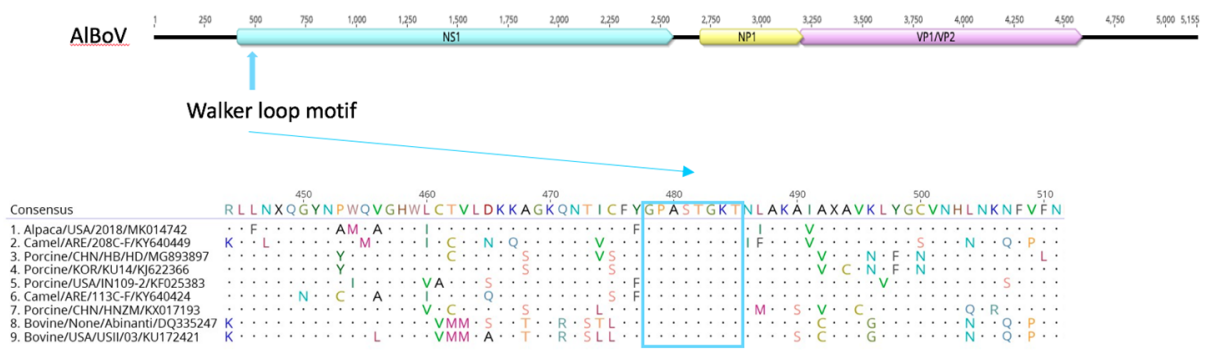

b.

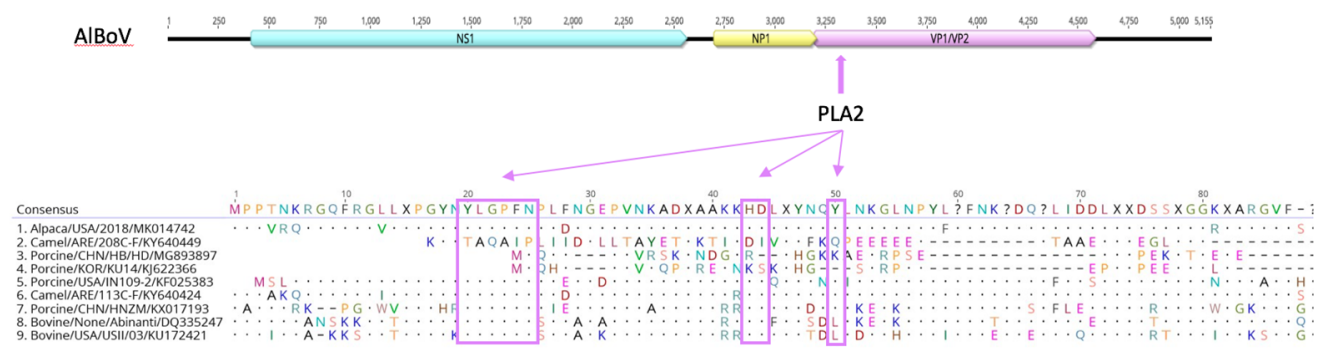

Figure 4. Detection of ATP and GTP-binding Walker-loop motif in NS1 protein (a) and Phospholipase A2 (PLA2) motif in N-terminal of VP1 protein (b). Dots indicate residues matching the consensus sequence and dashes represent gaps in the alignment.

A new species of UBoV was identified in an alpaca intestinal sample. Bocaparvoviruses cause respiratory and gastrointestinal infections in humans, bovines, and other animals. However, the causation of clinical disease in this alpaca farm is unclear. Establishing an association between the presence of $\mathrm{BoV}$ and clinical disease would require comprehensive PCR testing of the alpaca farms. Moreover, Koch's postulates is required to establish a virus-disease association. A causal association between the presence of $\mathrm{BoV}$ and clinical disease is often difficult due to prolonged viral shedding by the host after infection, high prevalence of BoV infection, and high rate of co-infections [35]. Nevertheless, the discovery of a new BoV will help in developing new PCR diagnostics to determine the prevalence of $\mathrm{BoV}$ in alpaca herds and also to develop vaccines to prevent clinical disease. Given the high mutation rate of BoVs and increasing domestication of alpacas, identification of a new BoV in alpaca presents a true risk of cross-species transmission to other mammals.

Author Contributions: Conceptualization: D.M.; Sample preparation and next generation sequencing: S.C.; next generation sequencing pipeline: N.L., M.H.; Formal analysis: D.K.; Phylogenetic trees: D.K., M.D.; Writing — original draft preparation: D.K.; writing—review and editing: D.M.; Case description and sample: D.B. and C.A.M.; Supervision: D.M.; Funding acquisition: D.M.

Funding: The study was partially supported by Marthaler's start up fund.

Acknowledgments: The authors would like to thank the Kansas State Veterinary Diagnostic Laboratory and Tufts University for supporting the project.

Conflicts of Interest: The authors declare no conflict of interest.

\section{References}

1. Wang, Y.; Zhao, J.; Zheng, M.; Liu, Z.; Yuan, J.; Zhao, J.; Shen, Q.; Fan, Z.; Jiang, L. Genome Sequence of a Porcine Bocavirus Detected in Feces of Domestic Minks in China. Genome Announc. 2017, 5, e1170-17. [CrossRef] [PubMed]

2. Lau, S.K.; Ahmed, S.S.; Yeung, H.C.; Li, K.S.; Fan, R.Y.; Cheng, T.Y.; Cai, J.P.; Wang, M.; Zheng, B.J.; Samson, S.Y.W.; et al. Identification and Interspecies Transmission of a Novel Bocaparvovirus among Different Bat Species in China. J. Gen. Virol. 2016, 97, 3345-3358. [CrossRef] [PubMed] 
3. Woo, P.C.; Lau, S.K.; Tsoi, H.-W.; Patteril, N.G.; Yeung, H.C.; Joseph, S.; Wong, E.Y.M.; Muhammed, R.; Chow, F.W.N. Two novel dromedary camel bocaparvoviruses from dromedaries in the Middle East with unique genomic features. J. Gen. Virol. 2017, 98, 1349-1359.

4. Kapoor, A.; Mehta, N.; Esper, F.; Poljsak-Prijatelj, M.; Quan, P.L.; Qaisar, N.; Delwart, E.; Lipkin, W.L. Identification and characterization of a new Bocavirus species in Gorillas. PLoS ONE 2010, 5, e11948. [CrossRef] [PubMed]

5. Ao, Y.; Li, X.; Li, L.; Xie, X.; Jin, D.; Yu, J.; Lu, S.; Duan, Z. Two novel bocaparvovirus species identified in wild Himalayan marmots. Sci. China Life Sci. 2017, 60, 1348-1356. [CrossRef]

6. Gunn, L.; Collins, P.J.; Fanning, S.; McKillen, J.; Morgan, J.; Staines, A.; O'Shea, H. Detection and characterisation of novel bocavirus (genus Bocaparvovirus) and gastroenteritis viruses from asymptomatic pigs in Ireland. Infect. Ecol. Epidemiol. 2015, 5, 27270. [CrossRef] [PubMed]

7. Zhang, C.; Song, F.; Xiu, L.; Liu, Y.; Yang, J.; Yao, L.; Peng, J. Identification and characterization of a novel rodent bocavirus from different rodent species in China. Emerg. Microbes Infect. 2018, 7, 48. [CrossRef] [PubMed]

8. Cotmore, S.F.; Agbandje-McKenna, M.; Chiorini, J.A.; Mukha, D.V.; Pintel, D.J.; Qiu, J.; Soderlund-Venermo, M.; Tattersall, P.; Tijssen, P.; Gatherer, D.; et al. The family Parvoviridae. Arch. Virol. 2014, 159, 1239-1247. [CrossRef]

9. Cheng, W.-X.; Li, J.-S.; Huang, C.-P.; Yao, D.-P.; Liu, N.; Cui, S.-X.; Jin, Y.; Duan, Z.-J. Identification and nearly full-lengthg characterization of novel porcine Bocaviruses. PLoS ONE 2010, 5, e13583. [CrossRef]

10. Principi, N.; Piralla, A.; Zampiero, A.; Bianchini, S.; Umbrello, G.; Scala, A.; Bosis, S.; Fossali, E.; Baldanti, F. Bocavirus infection in otherwise healthy children with respiratory disease. PLoS ONE 2015, 10, e0135640. [CrossRef]

11. Kailasan, S.; Halder, S.; Gurda, B.; Bladek, H.; Chipman, P.R.; McKenna, R.; Brown, K.; Agbandje-McKenna, M. Structure of an enteric pathogen, bovine parvovirus. J. Virol. 2015, 89, 2603-2614. [CrossRef]

12. Binn, L.N.; Lazar, E.C.; Eddy, G.A.; Kajima, M. Recovery and characterization of a minute virus of canines. Infect. Immun. 1970, 1, 503-508.

13. McClenahan, S.D.; Scherba, G.; Borst, L.; Fredrickson, R.L.; Krause, P.R.; Uhlenhaut, C. Discovery of a Bovine Enterovirus in Alpaca. PLoS ONE 2013, 8, e68777. [CrossRef]

14. Alpaca Owners Association Inc Homepage. Available online: https://www.alpacainfo.com/about/statistics/ alpacas-us (accessed on 22 May 2019).

15. Crossley, B.M.; Mock, R.E.; Callison, S.A.; Hietala, S.K. Identification and characterization of a novel alpaca respiratory coronavirus most closely related to the human coronavirus 229E. Viruses 2012, 4, 3689-3700. [CrossRef]

16. Brito, B.P.; Gardner, I.A.; Hietala, S.K.; Crossley, B.M. Variation in Bluetongue virus real-time reverse transcription polymerase chain reaction assay results in blood samples of sheep, cattle, and alpaca. J. Vet. Diagn. Investig. 2011, 23, 753-757. [CrossRef]

17. Kapil, S.; Yeary, T.; Evermann, J.F. Viral diseases of new world camelids. Vet. Clin. N. Am. Food Anim. Pract. 2009, 25, 323-337. [CrossRef]

18. Jin, L.; Cebra, C.K.; Baker, R.J.; Mattson, D.E.; Cohen, S.A.; Alvarado, D.E.; Rohrmann, G.F. Analysis of the genome sequence of an alpaca coronavirus. Virology 2007, 365, 198-203. [CrossRef]

19. Barrington, G.M.; Allen, A.J.; Parish, S.M.; Tibary, A. Biosecurity and biocontainment in alpaca operations. Small Rum. Res. 2006, 61, 217-225. [CrossRef]

20. Wernery, U.; Kaaden, O.R. Foot-and-mouth disease in camelids: A review. Vet. J. 2004, 168, $134-142$. [CrossRef]

21. Hause, B.M.; Collin, E.A.; Anderson, J.; Hesse, R.A.; Anderson, G. Bovine rhinitis viruses are common in U.S. cattle with bovine respiratory disease. PLOS ONE 2015, 10, e0121998. [CrossRef]

22. Neill, J.D.; Bayles, D.O.; Ridpath, J.F. Simultaneous rapid sequencing of multiple RNA virus genomes. J. Virol. Methods 2014, 201, 68-72. [CrossRef]

23. Knutson, T.P.; Velayudhan, B.T.; Marthaler, D.G. A porcine enterovirus G associated with enteric disease contains a novel papain-like cysteine protease. J. Gen. Virol. 2017, 98, 1305-1310. [CrossRef]

24. Bolger, A.M.; Lohse, M.; Usadel, B. Trimmomatic: A flexible trimmer for Illumina sequence data. Bioinformatics 2014. [CrossRef] 
25. Joshi, N.; Fass, J. Sickle-A Windowed Adaptive Trimming Tool for FASTQ Files Using Quality. 2011. Available online: http://github.com/najoshi/sickle (accessed on 2 July 2019).

26. Buffalo, V. Scythe-A Bayesian Adapter Trimmer. 2011. Available online: http://github.com/vsbuffalo/scythe (accessed on 2 July 2019).

27. Wood, D.E.; Salzberg, S.L. Kraken: Ultrafast metagenomic sequence classification using exact alignments. Genome Biol. 2014, 15, R46. [CrossRef]

28. Katoh, K.; Standley, D.M. MAFFT Multiple Sequence Alignment Software Version 7: Improvements in Performance and Usability. Mol. Biol. Evol. 2013, 30, 772-780. [CrossRef]

29. Kearse, M.; Moir, R.; Wilson, A.; Stones-Havas, S.; Cheung, M.; Sturrock, S.; Buxton, S.; Cooper, A.; Markowitz, S. Geneious Basic: An integrated and extendable desktop software platform for the organization and analysis of sequence data. Bioinformatics 2012, 28, 1647-1649. [CrossRef]

30. Martin, D.P.; Murrell, B.; Golden, M.; Khoosal, A.; Muhire, B. RDP4: Detection and analysis of recombination patterns in virus genomes. Virus Evol. 2015, 1, vev003. [CrossRef]

31. Shackelton, L.A.; Parrish, C.R.; Truyen, U.; Holmes, E.C. High rate of viral evolution associated with the emergence of carnivore parvovirus. Proc. Natl. Acad. Sci. USA 2005, 102, 379-384. [CrossRef]

32. Fasina, O.O.; Dong, Y.; Pintel, D.J. NP1 protein of the bocaparvovirus minute virus of canines controls access to the viral capsid genes via its role in RNA processing. J. Virol. 2015, 90, 1718-1728. [CrossRef]

33. Zádori, Z.; Szelei, J.; Lacoste, M.-C.; Li, Y.; Gariépy, S.; Raymond, P.; Allaire, M.; Nabi, I.R.; Tijssen, P. A Viral Phospholipase A2 Is Required for Parvovirus Infectivity. Dev. Cell 2001, 1, 291-302. [CrossRef]

34. Deng, X.F.; Dong, Y.M.; Yi, Q.H.; Huang, Y.; Zhao, D.; Yang, Y.B.; Tijssen, P.; Qiu, J.M.; Liu, K.Y.; Li, Y. The determinants for the enzyme activity of human parvovirus b19 phospholipase a2 (pla2) and its influence on cultured cells. PLoS ONE 2013, 8, e61440. [CrossRef]

35. Castrignano, S.B.; Nagasse-Sugahara, T.K. The metagenomic approach and causality in virology. Rev. Saúde Pública 2015, 49, 21. [CrossRef]

(C) 2019 by the authors. Licensee MDPI, Basel, Switzerland. This article is an open access article distributed under the terms and conditions of the Creative Commons Attribution (CC BY) license (http://creativecommons.org/licenses/by/4.0/). 